\title{
Humanização e Acolhimento em Saúde Mental: Percepção dos Usuários.
}

\author{
Cabral, Mariana Pompílio Gomes; Maia Neto, José Pereira; Costa, Juliana Pessoa; Jorge, \\ Maria Salete Bessa; Caminha, Emília C. Carvalho Rocha; Paula, Milena Lima de \\ Universidade Estadual do Ceará — mari.pompilio@gmail.com
}

Introdução: o acolhimento, visto como paradigma em saúde coletiva, deve ter início na recepção do serviço e em todo o processo de tratamento, incluindo a relação dos trabalhadores com os usuários. Deste modo, acolhimento implica no processo de responsabilização, na intervenção resolutiva e a humanização do atendimento, através da escuta qualificada dos problemas de saúde dos usuários. Sendo assim, humanizar na atenção à saúde é compreender cada pessoa em sua singularidade, tendo necessidades específicas, levando em conta seus valores e vivências como únicos, evitando quaisquer formas de discriminação negativa, de perda da autonomia, preservando a dignidade do ser humano. a humanização no serviço de saúde possibilita uma transformação cultural da gestão e das práticas desenvolvida nos estabelecimentos de saúde, assumindo uma postura ética entre os trabalhadores e o respeito ao usuário. Todavia, na rede básica de saúde o modo de assistência da equipe nem sempre favorece a integralidade, devido as várias dificuldades de tais equipes em desenvolver um trabalho mais coeso, que privilegie uma atenção psicossocial, afastando-se do modelo biomédico e na fragmentação dos saberes. Objetivo: Compreender e analisar a percepção dos usuários sobre humanização no acolhimento em saúde mental. Metodologia: Trata-se de um estudo que faz parte de uma pesquisa ampla denominada "Organização da rede regional de saúde e sua interface com a saúde mental no estado do ceará: dimensão política, econômica, social, organizacional, tecnológica e simbólica", com financiamento do CNPq/MS. É uma pesquisa qualitativa realizada com trabalhadores da ESF e do CAPS, bem como usuários em tratamento e seus familiares nos municípios de Fortaleza e Eusébio. para a coleta de dados utilizou-se a entrevista semiestruturada e a análise dos dados seguiu a orientação da Análise de Conteúdo. o estudo foi aprovado pelo Comitê de Ética em Pesquisa (CEP) da Universidade Estadual do Ceará (UECE). Resultados: na percepção dos usuários, o acolhimento humanizado pode ser alcançado por meio de um atendimento acolhedor, mediante responsabilização das equipes, com atitudes éticas e flexíveis. Considera-se que o serviço de saúde apresenta falta de profissionais preparados para a realização do acolhimento. Outro aspecto destacado pelos usuários é que o profissional de saúde não só compreenda exclusivamente a cura de doenças, mas também o alívio ou minimização do sofrimento, promoção e manutenção da saúde. Conclusão: Ressalta-se, por fim, que para garantir um atendimento humanizado é necessário uma equipe qualificada e capacitada, uma quantidade suficiente de profissionais, estrutura física adequada e comprometimento com a atenção integral da saúde dos cidadãos.

Cabral, Mariana Pompílio Gomes; Maia Neto, José Pereira; Costa, Juliana Pessoa; Jorge, Maria Salete Bessa; Caminha, Emília C. Carvalho Rocha; Paula, Milena Lima de. Humanização e Acolhimento em Saúde Mental: Percepção dos Usuários.. In: Anais do Congresso Internacional de Humanidades \& Humanização em Saúde [= Blucher Medical Proceedings, num.2, vol.1]. São Paulo: Editora Blucher, 2014. ISSN 2357-7282 